\title{
Toxicidade córneo-conjuntival do colírio de iodo-povidona:
}

\section{estudo experimental}

\author{
Corneal and conjunctival toxicity of povidone-iodine eye drops
}

\author{
Namir Clementino Santos ${ }^{1}$ \\ Luciene Barbosa de Sousa ${ }^{2}$ \\ Denise de Freitas ${ }^{3}$ \\ Moacyr Pezati Rigueiro4 \\ Marinho Jorge Scarpi ${ }^{5}$
}

\section{R E S U M O}

Objetivo: Avaliar a toxicidade ocular do colírio de iodo-povidona a 2,5\% e a $0,5 \%$ sobre a superfície ocular, na regeneração do epitélio corneal e as alterações histopatológicas da córnea. Métodos: Realizaram-se estudos experimentais consecutivos em coelhos albinos, nos quais se fez a ablação do epitélio de uma área circular central da córnea de $6,5 \mathrm{~mm}$ de diâmetro. Em cada experimento foram utilizados 20 animais ( 40 olhos), sendo que no olho direito foi instilado o colírio de iodo-povidona (caso) e no olho esquerdo água destilada (controle), em intervalos de uma hora, durante três dias consecutivos. Durante o experimento, os animais foram submetidos a exames biomicroscópicos diários para avaliação da superfície córneoconjuntival e realização de fotografias seriadas da área sem epitélio, corada com fluoresceína, para medida da área projetada da lesão com auxílio de analisador de imagem computadorizado. No final do experimento, os animais foram sacrificados para avaliação histopatológica das córneas. Resultados: O colírio de iodo-povidona a 2,5\% comprometeu a regeneração epitelial, causou conjuntivite em 100\% dos olhos, com produção de secreção de aspecto mucoso em $80 \%$, ceratite ponteada em $40 \%$ e edema estrômico leve em $10 \%$ dos casos. Os achados histopatológicos foram úlcera de córnea, degeneração hidrópica das células endoteliais e infiltrado inflamatório com predomínio de eosinófilos em $100 \%$ dos casos. Nos olhos em que se instilou iodo-povidona a $0,5 \%$, assim como nos controles, observou-se completa regeneração da lesão epitelial $(\mathrm{p}<0,001)$ após 72 horas do início do experimento. Doponto de vista histopatológico, epitelização normal em todos os casos e controles, em apenas um caso observou-se discretoinfiltrado de leucócitos perilímbicos. Conclusão: A toxicidade ocular do colírio de iodo-povidona é dependente da concentração da solução, sendo que o colírio a 2,5\% mostrou-se inadequado para utilização em intervalos de uma hora e a $0,5 \%$ não causou toxicidade significante.

Trabalho realizado no Departamento de Oftalmologia Setor de Doenças Externas Oculares e Córnea, Universidade Federal de São Paulo - UNIFESP.

Doutora em Medicina pela Universidade Federal de São Paulo - UNIFESP.

${ }^{2}$ Professora do Curso de Pós-Graduação e Coordenadora do Setor de Doenças Externas Oculares e Córnea da Universidade Federal de São Paulo - UNIFESP.

${ }^{3}$ Professora do Curso de Pós-Graduação e Livre Docente da Universidade Federal de São Paulo - UNIFESP.

${ }^{4}$ Professor Adjunto do Departamento de Patologia da Universidade Federal de São Paulo - UNIFESP.

${ }^{5}$ Professor do Curso de Pós-Graduação e Livre Docente da Universidade Federal de São Paulo - UNIFESP.

Endereço para correspondência: Rua Prof. Clemente Fortes, 2390 - Teresina (PI) CEP 64051-030

E-mail: namirsantos@ig.com.br

Recebido para publicação em 09.05.2002

Aceito para publicação em 11.09.2002

Nota Editorial: Pela análise deste trabalho e por sua anuência na divulgação desta nota, agradecemos ao Dr. Breno Barth.
Descrittores:Povidona-iodo/toxicidade;Soluções oftálmicas/toxicidade;Epitéliodacómea/ efeitos dedrogas; Conjuntiva/efeitos de drogas; Experimentaçãoanimal;Coelhos
O elemento natural iodo tem sido usado há mais de 150 anos para prevenir infecções e tratar feridas ${ }^{(1)}$.

Seu uso inicial produziu impacto devido a sua rápida ação microbicida sob várias condições adversas, com eficácia comprovada contra a maioria das bactérias, fungos, vírus, rickettsias e protozoários ${ }^{(1)}$.

O iodo, isoladamente, tem seu uso limitado pela baixa solubilidade em água e pela toxicidade ${ }^{(1-2)}$. Foi somente a partir do desenvolvimento dos 
iodoforos, pela ligação do iodo à macromolécula de polivinilpirrolidona (povidona), que o uso, em larga escala, deste microbicida tornou-se possível.

Algumas propriedades do iodo são alteradas e aprimoradas pela combinação do iodo com uma molécula carreadora, como a povidona. Estas soluções de iodo são chamadas iodophors (iodo; phor=carreadora). Os iodoforos apresentam melhor atividade antibacteriana, estabilidade, menor toxicidade, reduzida pressão de vapor, menos odor, coloração quase inexistente da área tratada, e tornaram possível a obtenção de várias diluições ${ }^{(1-2)}$. A introdução da solução de iodo-povidona em cirurgia oftalmológica ocorreu a partir da década de setenta, quando foi demonstrado sua eficácia na preparação das pálpebras e fronte para o ato cirúrgico ${ }^{(3)}$. Desde então, tem sido utilizada como agente preparatório para cirurgia oftálmica, e vários estudos clínicos e experimentais têm sugerido sua eficácia em diversas concentrações no tratamento de úlceras de córnea $^{(4-7)}$ e infecções da superfície ocular ${ }^{(8)}$.

Considerando espectro de ação do iodo-povidona o estudo de potenciais toxicidades oculares, decorrentes de seu uso em regime de doses freqüentes por período prolongado, seguramente, colaborarão para expandir o conhecimento do arsenal terapêutico à disposição dos oftalmologistas.

O objetivo deste trabalho foi estudar, em modelo experimental, a toxicidade ocular do colírio de iodo-povidona a 2,5\% e $0,5 \%$ e sua influência na reparação de defeitos epiteliais produzidos na área central da córnea em coelhos.

\section{MÉ T OD OS}

\section{Animais e materiais}

Realizaram-se estudos experimentais consecutivos em coelhos albinos da raça Nova Zelândia, espécie Oryctolagus caniculus, nos quais avaliou-se os efeitos do colírio de iodopovidona a 2,5\% e $0,5 \%$ sobre a superfície ocular, na regeneração do epitélio corneal e as alterações histopatológicas da córnea.

Os animais utilizados nos experimentos eram machos, com média de peso de 2,0kg e idade entre 3 e 4 meses, sem anormalidades oculares detectadas ao exame inicial com lâmpada de fenda (Zeiss).

Os animais foram anestesiados topicamente com a instilação de cloridrato de proximetacaína a $0,5 \%$ (Anestalcon ${ }^{\circledR}$ - Alcon Laboratórios do Brasil Ltda) seguida pela inserção de blefarostato (modelo Barraquer, Steel Inox ${ }^{\circledR}$, tamanho infantil) para adequada exposição ocular e realização de defeitos superficiais na porção central da córnea. A demarcação da área a ter o epitélio removido foi feita, sob magnificação (aumento de 16x da lâmpada de fenda), com marcador de zona óptica de 6,5mm (Steel Inox ${ }^{\circledR}$ ). O epitélio na área demarcada foi removido com lâmina de bisturi (Alcon ${ }^{\circledR}$ Surgical Blade 57CE0123). A eficácia da ablação epitelial foi controlada com a instilação de fluoresceínica sódica (Fluoresceína ${ }^{\circledR}$, Allergan Produtos Farmacêuticos Ltda).
Em cada experimento utilizou-se 20 animais (40 olhos), sendo que no olho direito foi instilado o colírio de iodopovidona (caso) e no olho esquerdo água destilada (controle), em intervalos de uma hora, durante três dias consecutivos.

Durante o experimento, os animais foram mantidos no biotério DPC-MEDLAB-Industria de Reagentes Ltda e tratados de acordo com as normas da Association for Research in Vision and Ophthalmology (ARVO) para o uso de animais em pesquisa.

As soluções de iodo-povidona foram manipuladas pela farmácia Ophthalmos a uma concentração de 2,5\% e $0,5 \%$ (PVP-I, Galena), diluídas em água destilada estéril q.s.p 100\% e tampão fosfato (fosfato monossódico monohidratado $0,37 \% \mathrm{e}$ fosfato dissódico $0,57 \%$, Merck $^{\circledR}$ ) e isotonizada com cloreto de sódio $0,46 \%\left(\right.$ Merck $\left.^{\circledR}\right)$, obtendo-se soluções estéreis com $\mathrm{pH}$ final entre 6,0 e 7,0 .

\section{Biomicroscopia}

Durante o período do estudo os animais foram submetidos a exame ocular, em lâmpada de fenda (Zeiss), diariamente, para avaliação da superfície córneo-conjuntival e do defeito epitelial. Para tal, ficha de avaliação foi desenvolvida e preenchida diariamente.

Para o exame clínico foi levado em consideração, a presença de ceratite ponteada, edema epitelial e estrômico, opacidade corneal, infiltrados, conjuntivite, secreção, reação folicular e papilar.

A padronização dos principais achados clínicos foi feita de acordo com:

Na Conjuntiva: A- Secreção: 0 , ausência; $(+)$, leve $=$ traços de secreção no fundo de saco conjuntival ou aderidas às margens palpebrais; $(++)$, moderada $=$ quantidade pequena de secreção, facilmente visível nas margens palpebrais e conjuntiva; $(+++)$, acentuada = quantidade grande de secreção conjuntival e palpebral, permitindo ainda, observação do bulbo ocular; $(++++)$, intensa $=$ quantidade excessiva de secreção conjuntival e palpebral, dificultando a abertura da fenda palpebral. B- Conjuntivite: 0, ausente; (+), leve= injeção dos vasos conjuntivais em grau discreto; $(++)$, moderada= injeção dos vasos conjuntivais em graus moderado e discreto edema; $(+++)$, acentuada $=$ moderada a intensa injeção dos vasos conjuntivais; quemose leve; $(++++)$, intensa= injeção intensa dos vasos conjuntivais; quemose extensa e blefarite. C-. Reação folicular: 0 , ausente; $(+)$, leve $=$ menos de cinco folículos na conjuntiva palpebral inferior; $(++)$, moderada $=$ mais de cinco folículos na conjuntiva palpebral inferior; discreta reação folicular $(<5)$ na pálpebra superior; $(+++)$, acentuada= inúmeros folículos nas pálpebras superior e inferior. D - Reação papilar: 0 , ausente; $(+)$, leve $=$ reação papilar discreta na conjuntiva palpebral inferior; $(++)$, moderada $=$ reação papilar moderada na conjuntiva palpebral inferior e discreta na pálpebra superior; $(+++)$, acentuada $=$ reação papilar acentuada envolvendo a pálpebra superior e inferior.

Na Córnea: A- Edema epitelial/ qualidade do epitélio em regeneração: 0 , cicatrização normal do epitélio; $(+)$, leve= edema 
epitelial visível por retroiluminação e não por iluminação direta; $(++)$, moderada= epitélio grosseiramente opacificado e irregular; $(+++)$, acentuado= epitélio grosseiramente opacificado e irregular. B- Edema estrômico: 0, ausente; (+), leve= edema envolvendo terço anterior da córnea com microbolhas epiteliais vistas por retroiluminação; $(++)$, moderado= córnea de espessura difusamente aumentada, com preservação da transparência; $(+++)$, acentuada= córnea acentuadamente edemaciada, com perda da transparência, dobras de Descemet e irregularidades epiteliais. C-Ceratite ponteada: 0 , ausente; $(+)$, leve= ceratite que envolve área correspondente a um quadrante da córnea ou menos; $(++)$, moderada $=$ envolve área que corresponde a dois quadrantes da córnea; $(+++)$, acentuada $=$ difusa, envolvendo três ou mais quadrantes da córnea. D- Infiltrado: 0 , ausente; $(+)$, leve $=$ infiltrado menor ou igual a $2 \mathrm{~mm}$, sem reação da câmara anterior; $(++)$, moderado= infiltrado maior que $2 \mathrm{~mm}$, com reação inflamatória tecidual perilesional, edema local, reação de câmara anterior; $(+++)$, acentuado= infiltrados múltiplos ou difuso, com diminuição da transparência da córnea.

Na íris: A- Irite: 0, ausente; (+), leve= hiperemia da íris; (++), moderada $=$ hiperemia e proeminência dos vasos irídicos; $(+++)$, acentuada $=$ hiperemia e proeminência dos vasos irídicos com presença de células na câmara anterior; $(++++)$, intensa= hipópio.

\section{Medida do defeito epitelial}

Durante a avaliação clínica diária realizaram-se, também, fotografias seriadas da área corneal sem epitélio, corada com fluoresceína, imediatamente após a realização do defeito epitelial e posteriormente a cada 24 horas encerrando-se com o término da experimentação, 72 horas depois.

As fotografias foram realizadas com um sistema de macrofotografia (lente macro $100 \mathrm{~mm}+3.5$ Yashica-Contax, foco $40 \mathrm{~cm}$, flash eletrônico Vivitar e filme Kodakolor Gold 100 ASA) para posterior medida da área da lesão corneal através de perimetria computadorizada.

Para a realização destas medidas, utilizou-se um sistema de análise de imagens computadorizadas (marca Leica ${ }^{\circledR}$. Leica Cambridge Ltd). As imagens foram digitalizadas através de uma câmara de vídeo digital de alta resolução acoplada a uma base graduada. A calibração do equipamento foi feita através da tomada de várias medidas do diâmetro da lesão corneal no início do experimento, considerando-se que este valor foi de $6,5 \mathrm{~mm}$. Após a calibração, as imagens foram então gravadas na memória do computador. A lesão corneal foi contornada com o "mouse" do computador e através de comandos do programa (Quantimet 500 IW, Image Processing and Analysis

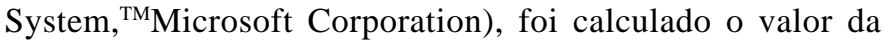
área projetada em $\mathrm{mm}^{2}$, obtendo-se uma área média de $34,07 \mathrm{~mm}^{2}$ para esta calibração.

\section{Procedimento para obtenção de tecidos}

Após os exames de controle, realizados 72 horas do início da experimentação, todos os animais foram mortos através de injeção endovenosa letal de cloridrato de lidocaína a $2 \%$
(Xylocaína ${ }^{\circledR}$ a $2 \%$. Astra Química e Farmacêutica Ltda), na veia marginal da orelha, para retirada in situ das córneas e fixação em Formol 10\% (Miyako, Farmacopéia Brasileira) para estudo anátomo-patológico.

As córneas foram identificadas com códigos de maneira que o patologista não tivesse acesso à informação se o espécime era caso ou controle.

\section{Anatomia patológica}

As córneas foram seccionadas ao meio e processadas para inclusão em parafina (Petrobrás, Indústria Brasileira). Foram realizados cortes de cinco micrometros de espessura, corados pela técnica de hematoxilina-eosina $(\mathrm{HE})$, para exame de microscopia óptica (microscópio Olympus CH30, com aumento de 40, 100 e 400 vezes). Todo o processamento histopatológico seguiu a rotina adotada no Departamento de Patologia da UNIFESP.

\section{Análise estatística}

Foram realizados os seguintes testes estatísticos: Teste de Friedman, Teste de Wilcoxon, Teste de Mann-Whitney, Quiquadrado de Pearson, Teste exato de Fisher. Para todos os testes estatísticos, o nível de significância adotado foi de alfa $<0,05$ ou $5 \%$.

\section{RES U L T A D O S}

No grupo em que se utilizou o colírio de iodo-povidona a $2,5 \%$, os valores das medianas da medida da área desepitelizada da córnea foram 37,7, 34,3 e 31,1 $\mathrm{mm}^{2}$ em 24, 48 e 72 horas, respectivamente, não havendo diferença estatisticamente significante $(p=0,074)$ nos diferentes intervalos. Os valores das medianas para os controles foram 12,6, 0,2 e 0,0 $\mathrm{mm}^{2} \mathrm{em} \mathrm{24,} 48$ e 72 horas, respectivamente, havendo diferença estatisticamente significante $(p<0,001)$. A mediana foi estatisticamente maior em 24 horas do que em 48 e 72 horas, porém não houve diferença estatisticamente significante entre 48 e 72 horas (Tabela 1). Comparando-se caso e controle, obteve-se diferença estatisticamente significante em todos os períodos, sendo a mediana do grupo em estudo sempre maior do que a do controle (Tabela 1).

Em relação aos valores das medianas para as medidas da área da lesão corneal no grupo PVP-I 0,5\% foram 16,7, 1,0 e $0,0 \mathrm{~mm}^{2}$ para casos em 24,48 e 72 horas respectivamente, havendo diferença estatisticamente significante $(p<0,001)$ entre os valores ao longo do tempo. As medianas para o controle foram $11,7,0,0$ e $0,0 \mathrm{~mm}^{2}$ nos mesmos intervalos de tempo, havendo diferença estatisticamente significante $(p<0,001)$. A mediana foi maior em 24 horas em relação a 48 e 72 horas, porém não houve diferença estatisticamente significante entre as medianas de 48 e 72 horas (Tabela 2). Comparando-se casos e controles, obteve-se diferença estatisticamente significante em 24 ( $p=0,002), 48(p=0,001)$ e 72 horas $(p=0,043)$ de intervalo. Sendo a mediana de caso sempre maior que a do controle (Tabela 2). 


\begin{tabular}{|c|c|c|c|c|}
\hline \multirow[b]{2}{*}{ Grupo } & \multicolumn{3}{|c|}{ Medlanas (mínimo-máximo) } & \multirow[b]{2}{*}{ Valores de p(Teste de Friedman) } \\
\hline & $24 h$ & $48 h$ & $72 \mathrm{~h}$ & \\
\hline $\operatorname{Caso}(n=20)$ & $33,7 \quad(17,7-37,7)$ & $34,3 \quad(12,2-44,3)$ & $31,1 \quad(5,4-48,3)$ & $\begin{array}{l}0,074 \\
24 h=48 h=72 h\end{array}$ \\
\hline Controle $(n=20)$ & $12,6(7,2-34,8)$ & $0,2(0,0-6,6)$ & $0,0(0,0-1,0)$ & $\begin{array}{l}<0,001 * \\
24 h>48 h \\
24 h>72 h \\
48 h=72 h\end{array}$ \\
\hline $\begin{array}{l}\text { Valores dep } \\
\text { (TestedeWilcoxon) }\end{array}$ & $\begin{array}{r}\varangle 0,001^{*} \\
\text { caso>controle }\end{array}$ & $\begin{array}{r}\varangle 0,001 * \\
\text { caso>controle }\end{array}$ & $\begin{array}{r}\varangle 0,001 * \\
\text { caso>controle }\end{array}$ & \\
\hline
\end{tabular}

\begin{tabular}{|c|c|c|c|c|}
\hline \multirow[b]{2}{*}{ Grupo } & \multicolumn{3}{|c|}{ Medianas (mínimo-máximo) } & \multirow[b]{2}{*}{ Valores de p(Teste de Friedman) } \\
\hline & $24 h$ & $48 h$ & 72h & \\
\hline Caso $(n=20)$ & $16,7(7,6-26,4)$ & $1,0(0,0-11,5)$ & $0,0(0,0-11,6)$ & $\begin{array}{l}\varangle 0,001^{*} \\
24 h>48 h \\
24 h>72 h \\
48 h=72 h\end{array}$ \\
\hline Controle $(n=20)$ & $11,7(6,9-18,7)$ & $0,0(0,0-2,2)$ & $0,0(0,0-0,0)$ & $\begin{array}{l}<0,001 * \\
24 h>48 h \\
24 h>72 h \\
48 h=72 h\end{array}$ \\
\hline $\begin{array}{l}\text { Valores dep } \\
\text { (TestedeWilcoxon) }\end{array}$ & $\begin{array}{r}0,002^{*} \\
\text { caso>controle }\end{array}$ & $\begin{array}{r}0,001^{*} \\
\text { caso>controle }\end{array}$ & $\begin{array}{r}0,043^{*} \\
\text { casoxcontrole }\end{array}$ & \\
\hline
\end{tabular}

Comparando-se as medidas da área, nos olhos em que se instilou o colírio a $2,5 \%$ e $0,5 \%$ (Figura 1 ), observou-se que os valores foram significantemente superiores para o colírio de iodo-povidona na concentração de $2,5 \%$ em relação a $0,5 \%$.

Na avaliação em lâmpada de fenda, observou-se a persistência de defeito epitelial em $100 \%$ dos casos em que se instilou a solução de iodo-povidona a $2,5 \%$. Conjuntivite

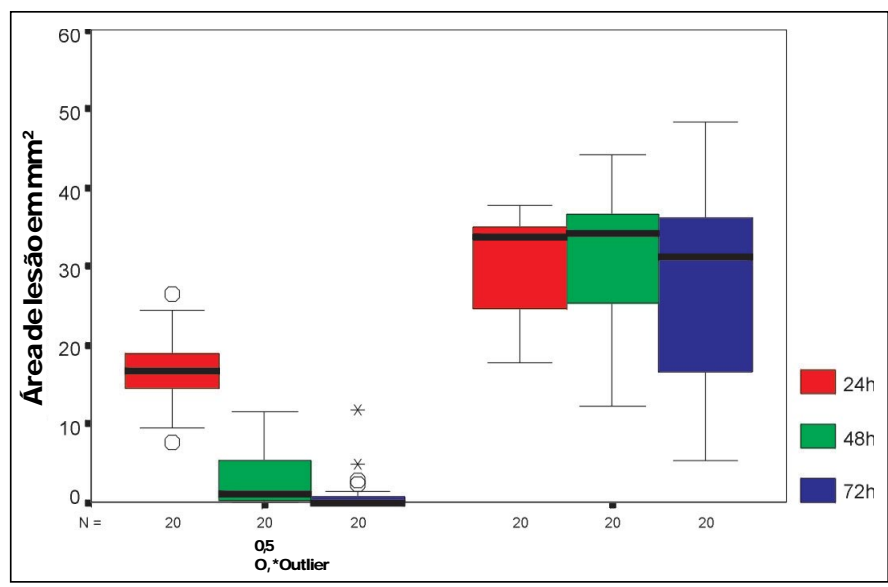

Figura 1-Medida da área da lesão corneal $\left(\mathrm{mm}^{2}\right)$ nos olhos em que seinstilaramiodo-povidonaa 0,5\%e2,5\%,em24,48e 72 horas. Teste de Mann-Whitneyp $<0,001$ (2,5\% >0,5\%, paratodos os tempos) ocorreu em $100 \%$ dos casos e esteve presente a partir das primeiras 24 horas de uso do colírio, sendo que no $3^{\circ}$ dia de observação foi considerada leve em $25 \%$ dos casos, moderada em $60 \%$ e acentuada em $15 \%$. Secreção branca, de aspecto mucoso, foi observada em $80 \%$ dos casos após 72 horas de uso da medicação, sendo que em metade dos casos apareceu nas primeiras 24 horas e nos demais casos foram observados a partir de 48 horas. Observou-se, ainda, edema estrômico leve em $20 \%$ dos casos e ceratite ponteada leve em $35 \%$ e moderada em 10\%, após 72 horas do início do experimento (Figura 2). Estes achados estão ilustrados na Tabela 3. Não foram observadas, em nenhum olho deste grupo, opacidades corneais, infiltrados, irite, reação folicular ou papilar.

Nos olhos em que se utilizou a solução de iodo-povidona a $0,5 \%$, observou-se regeneração completa do defeito epitelial em $80 \%$ dos casos após 72 horas de tratamento, ocorrendo diminuição das dimensões da lesão corneal ao longo deste período e reepitelização completa em $30 \%$ nas primeiras 48 horas. Outros achados foram conjuntivite leve em $65 \%$ e a presença de secreção branca de aspecto mucoso em $20 \%$ após 72 horas de uso da medicação (Figura 3). Não foram observadas, em nenhum olho deste grupo, opacidades corneais, infiltrados, irite, reação folicular ou papilar. Estes achados estão ilustrados na Tabela 4. 


\begin{tabular}{|c|c|c|c|c|}
\hline \multirow{3}{*}{$\begin{array}{l}\text { Defeitoepitelial } \\
\text { Conjuntivite }\end{array}$} & \multirow{2}{*}{$\begin{array}{c}\text { (+)/Leve } \\
\text { NOF } \\
0\end{array}$} & \multirow{2}{*}{$\begin{array}{c}\text { (+)/Moderado } \\
\text { No\% } \\
\text { O }\end{array}$} & $\begin{array}{c}\text { (+H)/Acentuado } \\
\text { No\% }\end{array}$ & $\begin{array}{l}\text { Total } \\
\text { No\% }\end{array}$ \\
\hline & & & $20(100)$ & $20(100)$ \\
\hline & $5(25)$ & $12(60)$ & 3 (15) & $16(80)$ \\
\hline Secreção & $3(15)$ & $9(45)$ & $4 \quad(20)$ & $16(80)$ \\
\hline Edemaestrômico & $4(20)$ & 0 & 0 & 4 (20) \\
\hline Ceratiteponteada & $7(35)$ & $2(10)$ & $\mathbf{0}$ & 9 (45) \\
\hline Infiltrado & 0 & 0 & 0 & 0 \\
\hline Inite & $\mathbf{0}$ & $\mathbf{0}$ & $\mathbf{0}$ & $\mathbf{0}$ \\
\hline Folículos & $\mathbf{0}$ & $\mathbf{0}$ & $\mathbf{0}$ & $\mathbf{0}$ \\
\hline Papilas & $\mathbf{0}$ & $\mathbf{0}$ & $\mathbf{0}$ & $\mathbf{0}$ \\
\hline №,número;\%,porcen & & & & \\
\hline
\end{tabular}

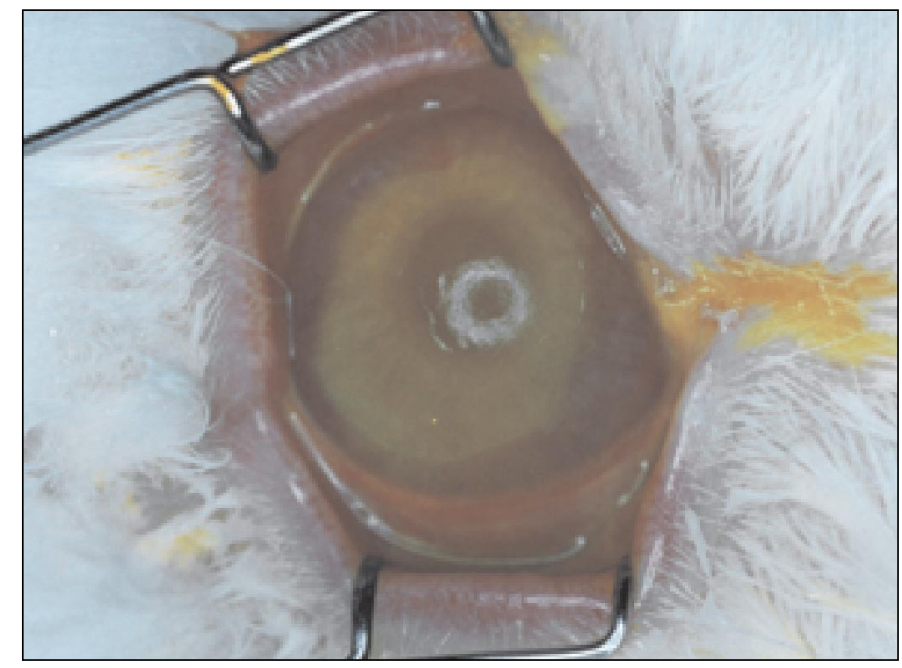

Figura 2 -Caso PVP-1 2,5\% após 72 horas de uso do colírio

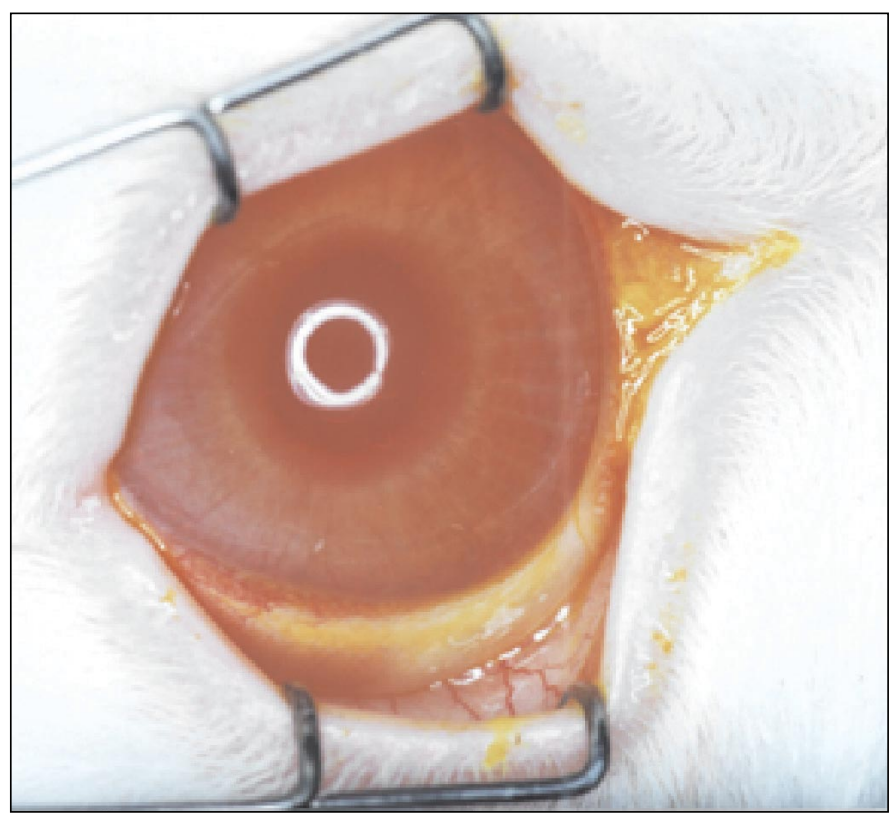

Figura 3-Caso PVP-1 0,5\% após 72 horas de uso do colírio
Todos os controles apresentaram regeneração total do defeito epitelial após 72 horas do início do experimento, sendo que $35 \%$ dos controles do grupo PVP-I 2,5\% reepitelizaram completamente em 48 horas, o mesmo ocorrendo em $90 \%$ dos controles do grupo PVP-I 0,5\%. Outro achado foi conjuntivite leve em 10\% dos olhos controles dos dois grupos (Figura 4).

$\mathrm{Na}$ avaliação anátomo-patológica das córneas em que se administrou o colírio de iodo povidona a $2,5 \%$, foram encontrados infiltrados inflamatórios (predominantemente de eosinófilos, com alguns linfócitos, macrófagos, monócitos e raros neutrófilos) em 100\% dos casos. (Figura 5, Tabela 5). Observando-se diferença estatisticamente significante $(p<0,001)$, dos casos em relação aos controles, quanto à presença de infiltrado inflamatório no estroma da córnea.

Em todos os casos deste grupo, observou-se degeneração hidrópica das células endoteliais (Figura 6). Nos controles, observou-se infiltrado de eosinófilos em $25 \%$ dos casos. Em todos os controles o epitélio estava completamente regenerado e o endotélio não apresentou alterações histológicas (Figura 8).

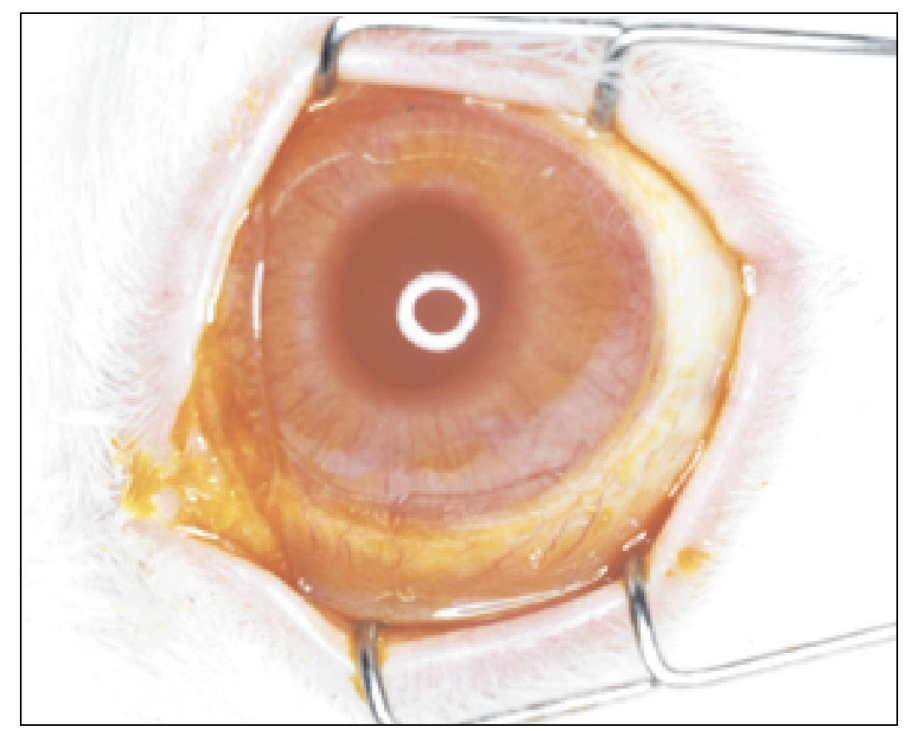

Figura 4-Controle após 72 horas 


\begin{tabular}{|c|c|c|c|c|}
\hline & $\begin{array}{l}\text { (+)/)Leve } \\
\text { No\% }\end{array}$ & $\begin{array}{c}\text { (+)/Moderado } \\
\text { No\% }\end{array}$ & $\begin{array}{c}\text { (+1)/Acentuado } \\
\text { No\% }\end{array}$ & $\begin{array}{l}\text { Total } \\
\text { N9\% }\end{array}$ \\
\hline Defeitoepitelial & $4(20)$ & 0 & 0 & $4(20)$ \\
\hline Conjuntivite & $13(65)$ & $\mathbf{0}$ & $\mathbf{0}$ & $13(65)$ \\
\hline Secreção & $4(20)$ & $\mathbf{0}$ & $\mathbf{0}$ & $4(20)$ \\
\hline Edemadoestrômico & 0 & 0 & $\mathbf{0}$ & 0 \\
\hline Ceratiteponteada & $\mathbf{0}$ & $\mathbf{0}$ & $\mathbf{0}$ & $\mathbf{0}$ \\
\hline Infiltrado & $\mathbf{0}$ & 0 & $\mathbf{0}$ & $\mathbf{0}$ \\
\hline Inite & $\mathbf{0}$ & $\mathbf{0}$ & $\mathbf{0}$ & $\mathbf{0}$ \\
\hline Folículos & $\mathbf{0}$ & $\mathbf{0}$ & $\mathbf{0}$ & $\mathbf{0}$ \\
\hline Papilas & $\mathbf{0}$ & $\mathbf{0}$ & $\mathbf{0}$ & $\mathbf{0}$ \\
\hline \multicolumn{5}{|c|}{ №,número;\%,porcentágem } \\
\hline
\end{tabular}

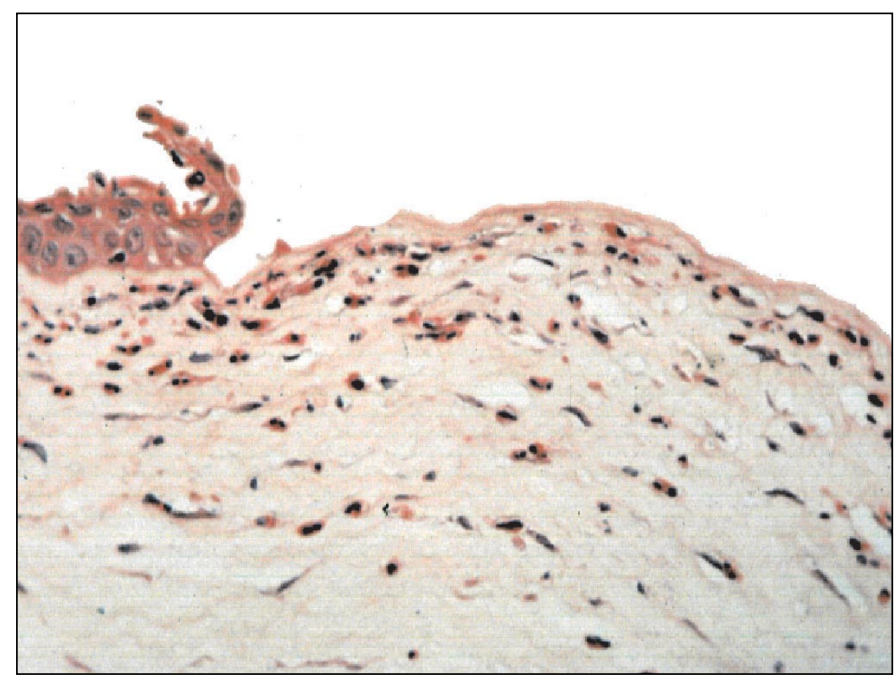

Figura 5-Borda do defeitoepitelial com infiltrado inflamatório, após uso do PVP-I a 2,5\% (HE, 400X)

\begin{tabular}{|c|c|c|c|c|}
\hline & \multicolumn{2}{|c|}{ Caso } & \multicolumn{2}{|c|}{ Controle } \\
\hline & No & $\%$ & No & $\%$ \\
\hline Sim & $\mathbf{2 0}$ & 100 & 5 & 25 \\
\hline Não & $\mathbf{0}$ & $\mathbf{0}$ & 15 & 75 \\
\hline Total & $\mathbf{2 0}$ & 100 & 20 & 100 \\
\hline \multicolumn{5}{|c|}{ Casos $\times$ Controlesp $<0,001$ (Qui-quadrado) } \\
\hline
\end{tabular}

Nas córneas do grupo PVP-I 0,5\% encontrou-se epitelização normal de todos os casos e controles, porém epitélio mais delgado nos casos. Exudato discreto de leucócitos perilímbico, com predomínio de eosinófilos foi observado apenas em um caso (Figuras 7). Não se observou diferença estatisticamente significante $(\mathrm{p}=1,000)$, entre casos e controles deste grupo, quanto à presença de infiltrado inflamatório no estroma (Tabela 6). Entretanto, comparando-se casos em que se instilou o colírio a 2,5\% com aqueles em que se instilou o colírio a

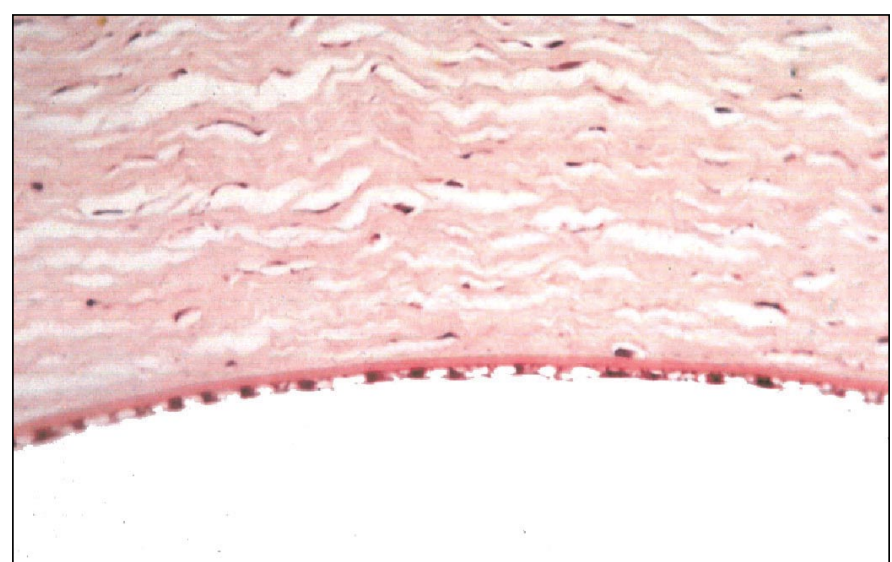

Figura6-Cómeacomvacuolizaçãocitoplasmáticadas células endoteliais após uso de PVP-I a 2,5\%(HE, 400X)

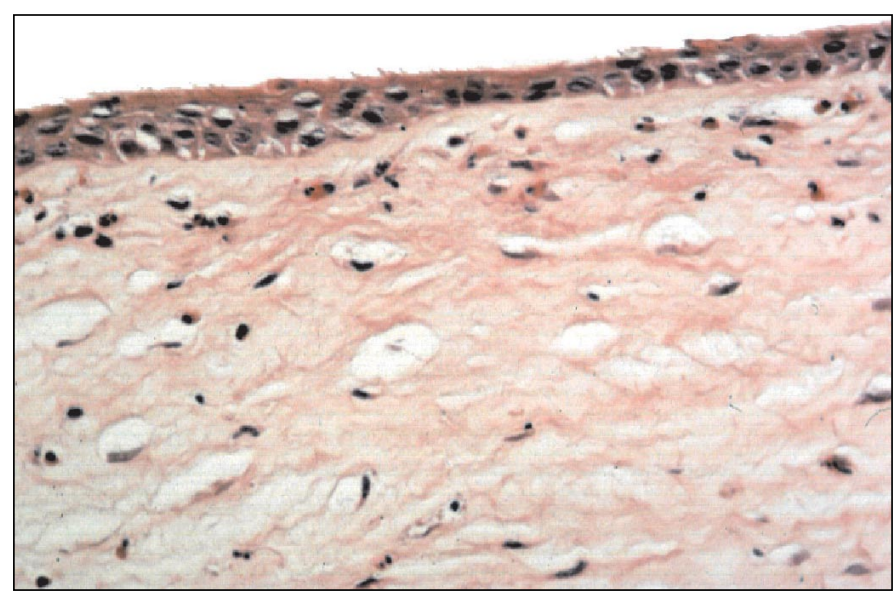

Figura 7-Cómea epitelizada com infiltrado Inflamatórioapós uso de PVP-I a 0,5\% (HE, 400X)

$0,5 \%$, encontramos diferença estatisticamente significante $(\mathrm{p}<0,001)$ quanto à presença do infiltrado inflamatório (Tabela 7$)$. Também houve diferença significante $(p=0,047)$ entre os controles dos dois grupos. Estroma e endotélio em todos os casos e controles apresentaram-se sem alterações (Figura 8). 


\begin{tabular}{|c|c|c|c|c|}
\hline & \multicolumn{2}{|c|}{ Caso } & \multicolumn{2}{|c|}{ Controle } \\
\hline & № & $\%$ & № & $\%$ \\
\hline Sim & 1 & 5 & 0 & 0 \\
\hline Não & 19 & 95 & 20 & 100 \\
\hline Total & 20 & 100 & 20 & 100 \\
\hline
\end{tabular}

\begin{tabular}{|c|c|c|c|c|}
\hline \multicolumn{5}{|c|}{$\begin{array}{c}\text { Tabela 7. Infiltradocomealna avaliação histopatológica, em } \\
\text { casos em que se instilou PVP-I a 2,5\% e 0,5\% }\end{array}$} \\
\hline & \multicolumn{2}{|c|}{ PVP-12,5\% } & \multicolumn{2}{|c|}{ PVP-10,5\% } \\
\hline & № & $\%$ & № & $\%$ \\
\hline $\operatorname{sim}$ & 20 & 100 & 1 & 5 \\
\hline Não & $\mathbf{0}$ & $\mathbf{0}$ & 19 & 95 \\
\hline Total & $\mathbf{2 0}$ & 100 & 20 & 100 \\
\hline \multicolumn{5}{|c|}{ Casos a 2,5\% >casos a 0,5\% p $<0,001$} \\
\hline
\end{tabular}

D I S CUSS ÃO

A razão de se estudar a toxicidade do iodo-povidona sobre a superfície ocular reside no fato de este ser um antimicrobiano de amplo espectro, com atividade comprovada contra a maioria das bactérias, vírus, fungos e protozoários ${ }^{(1)}$, além de ser um composto quimicamente estável, acessível, de manipulação relativamente fácil, e, portanto, sob certas circunstâncias, uma alternativa aos antibióticos tópicos no tratamento de infecções da superfície ocular e da córnea.

A eficácia do PVP-I no tratamento de conjuntivites agudas e úlceras de córnea foi sugerida em vários estudos clínicos e experimentais ${ }^{(4-6,9-10)}$.

O PVP-I causa baixa toxicidade ocular e tem uma longa história de segurança, como agente preparatório para cirurgia oftálmica $^{(3,7)}$. Entretanto, ainda se faz necessária a realização de pesquisas direcionadas para avaliar a relação concentração/toxicidade versus atividade antimicrobiana do iodo-povidona quando utilizado em regime de doses freqüentes por período prolongado.

Neste estudo, avaliaram-se, experimentalmente, os efeitos do colírio de iodo-povidona a $2,5 \%$ e $0,5 \%$ na regeneração epitelial após ablação de uma área superficial circular, do epitélio central da córnea, além de seus efeitos sobre a superfície ocular, e as alterações histopatológicas da córnea.

A escolha destas concentrações baseou-se, inicialmente, no trabalho experimental que mostrou eficácia in vitro da solução de PVP-I em concentrações de 0,5 a $2,5 \%$ contra isolados de Acanthamoeba, com atividade amebicida superior a clorexedina ${ }^{(8)}$. Motivados pelo crescente aumento do número de casos de ceratite por este protozoário, pela gravidade destas infecções, pelas dificuldades no tratamento, pela escassez de medicações tópicas e sistêmicas eficazes ${ }^{(8)}$, decidiu-se investigar os efeitos tóxicos potenciais do uso tópico do colírio de iodo-povidona, quando utilizado em intervalos de uma hora,

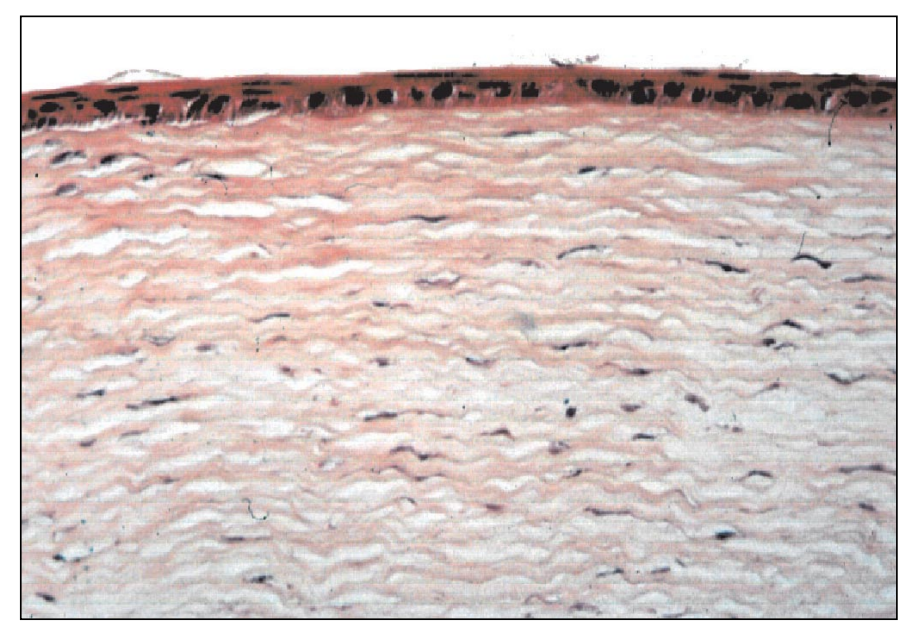

Figura8.Cómeacontrole, ausênciadecélulas inflamatónias (HE,400X)

tal qual o emprego de antibióticos fortificados na fase aguda de ceratites bacterianas graves ${ }^{(11)}$.

Adicionalmente, estudos in vitro e in vivo mostram boa atividade antimicrobiana do PVP-I, mesmo em concentrações reduzidas a $1 \%{ }^{(6)}$, a $5 \%{ }^{(9)}$, de 0,5 a $2,5 \%^{(8)}$, a $0,1 \%{ }^{(8)}$, de 0,1 a $1 \%(4)$, criando um campo para a realização de pesquisas para avaliar a viabilidade do uso da iodo-povidona como uma alternativa no tratamento de infecções oculares.

O fenômeno de atividade bactericida de diluições aumentadas é de difícil explicação. A química do iodo-povidona é complexa e ainda não é bem compreendida ${ }^{(4)}$. Uma hipótese é que diluições do iodo-povidona resultam no enfraquecimento da ligação do iodo ao polímero carreador com concomitante aumento na quantidade de iodo livre em solução ${ }^{(4)}$.

Neste estudo, avaliou-se a regeneração do epitélio corneal após trauma planejado, por meio da medida do tamanho da lesão epitelial após ablação de uma superfície circular constante no epitélio central da córnea. Este método constitui modelo de experimentação útil para o estudo dos mecanismos e influências de diversos fatores na cicatrização, inclusive o de ação de drogas ${ }^{(12)}$. As vantagens desse modelo podem-se justificar pela simplicidade da técnica e, igualmente, pela unicidade da população celular que reage à lesão ${ }^{(12)}$. Ainda, por razões de economia e manejo, o coelho é o animal mais popular para estudo dos efeitos do trauma no epitélio corneal.

Em estudos recentes, demonstrou-se que o PVP-I interage com a parede celular de microrganismos formando poros ou gerando interfaces sólido-líquidas, levando à perda de material citoplasmático e desnaturação enzimática. Também inibe a liberação de fatores químicos danosos e modula a reação inflamatória direcionada ao reparo tecidual ${ }^{(13)}$. O uso do colírio de iodo-povidona a $2,5 \%$ produziu significante retardo $(\mathrm{p}<0,001)$ da reparação do epitélio corneal quando comparado aos casos em que se usou o colírio a $0,5 \%$ e aos controles (Tabelas 1,2; Figura 1).

Sabendo-se que do tempo de cicatrização depende o diâmetro inicial da ferida e que a movimentação celular responsável 
pela reparação é proporcional ao perímetro do ferimento ${ }^{(12)}$, é lícito supor que a inibição da cicatrização do epitélio corneal após o uso do colírio de iodo-povidona a $2,5 \%$, no nosso período de estudo, foi devida principalmente à inibição da migração celular.

Os mecanismos pelos quais o PVP-I pode comprometer a cicatrização ainda não estão completamente compreendi$\operatorname{dos}^{(14)}$. Estudo in vivo, demonstrou significante inibição da migração, atividade fibroblástica e celularidade de feridas cutâneas in situ com o uso do PVP-I na concentração de 5\%, mas não com a solução a $1 \%$. Verificou-se também que a toxicidade celular é diretamente proporcional à concentração da solução utilizada ${ }^{(14)}$, concordando com os achados deste estudo, em que importante inibição da cicatrização do epitélio esteve presente com o uso do colírio a $2,5 \%$ e não a $0,5 \%$ (Tabelas 1,2; Figuras 2,3).

Os resultados obtidos referentes às medidas do defeito epitelial de casos e controles do experimento em que se usou o colírio a $0,5 \%$ (Tabela 2; Figuras 3 ) evidenciaram diferença estatisticamente significante nas medidas $(p<0,001)$ ao longo do tempo e também a ocorrência de completa cicatrização da lesão nos controles e na maioria dos casos após 72 horas. Entretanto, houve diferença estatisticamente significante $(p=0,001)$ de casos em relação a controles nas primeiras $24 \mathrm{e}$ 48 horas (casos>controles), significando que a reparação foi mais lenta nos casos que nos controles, observando-se cicatrização completa da lesão na maioria dos controles em 48 horas e de casos em 72 horas.

A literatura é relativamente escassa com relação aos efeitos tóxicos da utilização do colírio de iodo-povidona em mais de uma aplicação.

Estudo que avaliou a toxicidade ocular do PVP-I na concentração de $0,5 \%$ ou menos encontrou que este praticamente não causou irritação quando administrado seis vezes ao dia ${ }^{(15)}$. Entretanto, evidenciaram retardo na reparação do epitélio corneal em um dia, quando comparado à concentração de $0,33 \%$ e aos controles não tratados. Estes achados concordam com nossos resultados os quais mesmo com aplicações mais freqüentes, também, praticamente não produziram sinais de toxicidade ocular, apesar de retardarem a reparação do epitélio corneal em 24 horas em relação aos controles (Tabela 2; Figuras 3,4).

Por outro lado, em estudo no qual se utilizou a solução de iodo-povidona tópica a $0,1 \%$, de hora em hora, no tratamento de úlcera de córnea bacteriana induzida experimentalmente em animais, encontraram cura mais rápida e menor período de morbidade quando comparados aos olhos tratados com sulfato de gentamicina a $0,3 \%{ }^{(8)}$.

Os achados clínicos evidenciaram manifestações de toxicidade e/ou alergia ocular em ambos os casos (PVP-I a 2,5 e $0,5 \%)$, sendo estas mais acentuadas no grupo em que se instilou o colírio a $2,5 \%$ e caracterizada por persistência do defeito epitelial, conjuntivite, secreção de aspecto mucoso, ceratite ponteada e edema do estroma (Figura 2), os quais se acentuaram ao longo do tempo. Estas manifestações são comuns às reações alérgicas e tóxicas ${ }^{(16-17)}$. Entretanto, a presença do en- volvimento corneal em todos os casos, com comprometimento importante da regeneração do epitélio e ainda ceratite ponteada e edema do estroma, sugerem uma reação de natureza tóxica, uma vez que a córnea, nas reações alérgicas a medicamentos, não é afetada ou pode apresentar discreta ceratite ponteada em seu terço inferior ${ }^{(16)}$. Nas reações tóxicas, por sua vez, a córnea pode apresentar uma variedade de manifestações, que vão de ceratite ponteada leve a ceratopatia ulcerativa severa ${ }^{(16)}$. A distinção entre reação alérgica e tóxica a um dado agente pode ser difícil, porque algumas drogas podem desencadear ambas as reações por mecanismo concentração dependente ${ }^{(16-17)}$.

Estudos realizados por vários autores ${ }^{(18-19)}$ utilizando o colírio de iodo-povidona nas concentrações de $10 \%, 5 \%$ e $2,5 \%$, em única aplicação, não evidenciaram toxicidade local. Entretanto, quando instilado não diluído e repetidamente no fundo de saco conjuntival de olhos de coelho, causou inflamação conjuntival importante, mas nenhuma alteração clínica foi observada nas diluições de 1:1 e 1:3(20). No nosso esquema de aplicação, conjuntivite foi observada em $100 \%$ dos casos em que se instilou o colírio a 2,5\% e esteve presente, em grau leve, em mais de $50 \%$ dos olhos em que se instilou o colírio a $0,5 \%$ e, portanto, apesar de não comprometer a regeneração do epitélio, nesta concentração, pode causar discreta irritação ocular (Figura 3).

Os achados anátomo-patológicos das córneas em que se instilou PVP-I a 2,5\% confirmam as observações clínicas pela presença de infiltrado inflamatório no estroma, marcado pelo predomínio de eosinófilos, de alguns linfócitos e mononucleares (macrófagos e monócitos) e raros neutrófilos (Figura 5).

A resposta inflamatória linfócito-macrófago é característica da reação de hipersensibilidade ${ }^{(21)}$, e os eosinófilos estão classicamente associados às reações alérgicas e infecções parasitárias ${ }^{(21-22)}$. Neste estudo, observou-se a presença de infiltrado eosinofílico no estroma corneal em freqüência significativamente maior $(\mathrm{p}<0,001)$ nos casos em que se instilou o colírio a $2,5 \%$ que a $0,5 \%$ (Tabela 7 ). Sabendo-se que o desenvolvimento de uma reação alérgica a determinada droga independe da dose e da duração do tratamento, podendo estes apenas alterar a intensidade desta reação e que, caracteristicamente, desenvolve-se após exposições repetidas ao agente e a um tempo variável de sensibilização ${ }^{(23)}$, é lícito afirmar que, é improvável que a presença deste infiltrado resulte de um processo alérgico desencadeado pela medicação, uma vez que este não se desenvolveu nos casos em que se instilou o colírio a $0,5 \%$.

Embora eosinófilos tenham sido descritos em pacientes portadores de uma variedade de doenças oftálmicas não alérgicas, pouco se conhece sobre seu verdadeiro significado patogênico ${ }^{(22)}$.

Estudos sugerem a existência de resposta inflamatória peculiar do tecido corneal caracterizada pela presença de infiltrado eosinofílico de intensidade variável não relacionado com doenças alérgicas ou parasitárias ${ }^{(22)}$. Postula-se a existência de substâncias quimiotáxicas de eosinófilos na córnea ${ }^{(22)}$.

A presença de infiltrado de eosinófilos no estroma corneal em um número estatisticamente significante $(\mathrm{p}=0,047)$ de con- 
troles deste grupo, em relação aos controles em que se instilou o colírio a $0,5 \%$, é difícil de explicar. Uma possibilidade que deve ser considerada é a entrada acidental do colírio no olho controle, induzida pelo próprio animal.

Outro achado histopatológico no grupo em que se instilou o colírio a $2,5 \%$ foi a presença de degeneração hidrópica das células endoteliais em todos os casos (Figura 7).

O edema celular ocorre quando as células são incapazes de manter a homeostase fluida e iônica, sendo considerada a primeira manifestação de quase todas as formas de lesão celular. Ao exame microscópico, vêem-se pequenos vacúolos claros dentro do citoplasma; estes representam segmentos distendidos e separados do retículo endoplasmático. Esse padrão de lesão denomina-se degeneração hidrópica ou vacuolar e constitui alteração celular reversível ${ }^{(21)}$. Na revisão da literatura, nacional e internacional, não se encontrou descrição desta alteração celular associada com o uso do PVP-I. Estudo descreveu esta alteração histopatológica em olhos de coelhos tratados com pHisoHex (hexaclorofeno) ${ }^{(23)}$.

Foi descrito também perda das células endoteliais, irregularidade no formato celular e marcante comprometimento endotelial nas córneas estocadas em meio de preservação suplementado com PVP-I a 5\%, $1 \%$ e $0,1 \%{ }^{(24)}$. Essas alterações, ou seja, perda de células endoteliais, certamente representam um quadro mais grave que o observado neste trabalho, em que os achados foram restritos a fenômenos degenerativos que, por definição, são reversíveis ${ }^{(21)}$. Diante destes achados, concluímos que, o PVP-I a 2,5\%, em intervalo de uma hora, foi tóxico e causou uma resposta inflamatória peculiar, caracterizada pela presença marcante de eosinófilos e degeneração hidrópica das células endoteliais.

No esforço de minimizar as alterações patológicas produzidas pela droga, várias concentrações do iodo-povidona têm sido avaliadas topicamente. Alguns investigadores concluíram que concentrações mais baixas são menos tóxicas e melhores toleradas ${ }^{(5,19-20)}$.

O presente estudo vislumbra encontrar uma diluição segura, que cause toxicidade mínima ou tolerável, possibilitando o uso do PVP-I no tratamento de infecções oculares. Entretanto, ainda é necessária a realização de novos estudos para sanar algumas dúvidas surgidas, como, por exemplo: qual a concentração e freqüência ideais considerando a eficácia da solução e a toxicidade? Qual a penetração do iodo nos tecidos oculares quando utilizado em concentrações reduzidas? E qual sua eficácia, nestas concentrações, contra determinados microrganismos? Outra sugestão, para estudos subseqüentes de toxicidade a superfície ocular de medicações tópicas é a realização de raspados conjuntivais para estudo citológico em lâminas ou através de citologia de impressão.

\section{A B S T R A C T}

Purpose: To evaluate ocular toxicity of povidone-iodine eye drops at a concentration of $2.5 \%$ and $0.5 \%$ and to investigate the effects on corneal epithelial wound healing and histopa- thological alterations. Methods: Each group (PVP-I $2.5 \%$ and $0.5 \%$ ) consisted of 20 rabbits. A central circular corneal epithelial defect of $6.5 \mathrm{~mm}$ diameter was created and the povidoneiodine eyedrops $(2.5 \%$ and 0.5$)$ instilled in the right eye and distilled water in the left eye (control) of each rabbit, every hour, during 3 days. Biomicroscopical examinations were performed every day, focussing on the corneoconjunctival surface and the diameter of the lesion, using fluoresceine eye drops, photodocumentation, and a computerized image analyzer. After the third day the rabbits were sacrified and the excised corneas histopathologically evaluated. Statistical evaluation was performed using Friedman, Mann-Witney, Wilcoxon, Fisher and Chi-squared tests. Results: Povidone-iodine eye drops, at a concentration of $2.5 \%$, caused an increase in the wound healing time $(\mathrm{p}=0.087)$ and conjuntivitis in $100 \%$ of the eyes with mucous secretion in $80 \%$, punctate ceratitis in $40 \%$, and discrete stromal edema in $10 \%$ of the cases. The histopathological examination showed corneal ulcers and vacuolic degeneration of the endothelial layer in $100 \%$, as well as an inflammatory infiltrate with eosinophils in $80 \%$ of the cases. The eyes treated with povidone-iodine eye drops at a concentration of $0.5 \%$ and the control eyes showed complete epithelial wound healing after 72 hours, and histopathologically normal epithelization. Only in one case, a discrete perilimbar leucocytic infiltrate was observed. Conclusion: The ocular toxicity of povidone-iodine eye drops is concentration-dependent. The use of the eye drop at a concentration of $2.5 \%$ is not adequate for daily and repetitive use. In contrast, at a concentration of $0.5 \%$ no toxicity was observed.

Keywords: Povidone-iodine/toxicity; Ophthalmic solutions/ toxicity; Epithelium corneal/drug effects; Conjunctiva/drug effects; Animal experimentation; Rabbits

\section{REFERE N C I A S}

1. Gershenfeld L. Povidone-iodine as a topical antiseptic. Am J Surg 1957; 94:938-9.

2. Shelanski HÁ, Shelanski MV. PVP-iodine: history, toxicity and therapeutic uses. J Int Coll Surg 1956;25:727-34.

3. Chasse RC, Ellis P. Iodophores and skin asepsis. Ann Ophthalmol 1970; 2:312-7.

4. Berkelman RL, Holland BW, Anderson RL. Increased bactericidal activity of dilute preparations of povidone-iodine solutions. J Clin Microbiol 1982;15:635-9.

5. Sharma LG, Goyal JK, Sharma U, Chandak GK, Nepalia LK. Evaluation of topical povidone-iodine versus gentamycin in staphylococcus coagulase positive corneal ulcers - an experimental study. Indian J Ophthalmol 1990;38:30-2.

6. Abel R Jr, Abel AD. Use of povidone-iodine in the treatment of presumptive adenoviral conjunctivitis. Ann Ophthalmol 1998;30:341-3.

7. Apt L, Isenberg S. Chemical preparation of skin and eye in ophthalmic surgery: an international survey. Ophthalmic Surg 1982;13:1026-9.

8. Gatti S, Cevini C, Bruno A, Penso G, Rama P, Scaglia M. In vitro effectiveness of povidone-iodine on Acanthamoeba isolates from human cornea. Antimicrob Agents Chemother 1998;42:2232-4.

9. Saggers BA, Stewart GT. Polyvinyl-pyrrolidone-iodine: an assessment of antibacterial activity. J Hyg (Lond) 1964; 62:509-18.

10. White JH, Stephens GM, Cinotti AA. The use of povidone-iodine for treatment of fungi in rabbit eyes. Ann Ophthalmol 1972;4:855-6.

11. Liesegang TJ. Bacterial keratitis. In: Kaufman HE, Barron BA, McDonald MD. The cornea. Louisiana: Butterworth-Heinemann; 1998. p.159-218. 
12. Guimarães $\mathrm{O}$. Um método de medida da velocidade de regeneração do epitélio corneano no coelho. Rev Bras Oftalmol 1991;50:40-6.

13. Schreier H, Erdos G, Reimer K, Köning B, Köning W, Fleischer W. Molecular effects of povidone-iodine on relevant microorganisms: an electron microscopic and biochemical study. Dermatology 1997;195(Suppl 2):111-6.

14. Viljanto J. Disinfection of surgical wounds without inhibition of normal wound healing. Arch Surg 1980;115:253-6.

15. York KK, Miller S, Gaster RN, Burstein NL. Polyvinylpyrrolidone iodine: corneal toxicology and epithelial healing in a rabbit model. J Ocul Pharmacol 1988;4:351-8.

16. Chang SD. Toxic conjunctivitis. In: Krachmer JH, Mannis MJ, Holland EJ. Cornea. St. Louis: Mosby-Year Book; 1997. p.847-56.

17. Abelson MB, Udell IJ. Allergic and toxic reactions. In: Albert DM, Jakobiec FA. Principles and practice of ophthalmology. Philadelphia: WB Saunders; 2000. p.781-803.
18. Wille H. Assessment of possible toxic effects of polyvinylpyrrolidone-iodine upon the human eye in conjunction with cataract extraction. An endothelial specular microscope study. Acta Ophthalmol (Copenh) 1982;60:955-60.

19. Mac Rae SM, Brown B, Edelhauser HF. The corneal toxicity of presurgical skin antiseptics. Am J Ophthalmol 1984;97:221-32.

20. Kiffney GT Jr, Hattaway AC. Povidone-iodine as an ophthalmic antiseptic. Surg Forum 1966;17:434-6.

21. Spencer WH. Ophthalmic pathology. $4^{a}$ ed. Philadelphia: WB Saunders; 1996.

22. Limberg MB, Margo CE, Lyman GH. Eosinophils in corneas removed by penetrating keratoplasty. Br J Ophthalmol 1986;70:343-6.

23. Browning CW, Lippas J. PhisoHex keratitis. AMA Arch Ophthalmol 1955; 53:817-24.

24. Garcia-Ferrer FJ, Murray PR, Pepose JS. Corneal endothelial toxicity of DexSol corneal storage médium supplemented with povidone-iodine. Arch Ophthalmol 1992;110:1519-20

\title{
XXIV Congresso do Hospital São Geraldo
}

\author{
9 a 11 de OUTUBRO de 2.003 \\ GRAN DARRELLMINAS HOTEL \\ BELO HORIZONTE-MG
}

IN FO RMAÇÕES: Tels.: (31) 3274-1550

E-mail: comunica@consultcom.com.br

Home page: www.hospitalsaogeraldo.com.br 